\title{
Information Asymmetry at Merge and Acquisition- An Investigation on Firms in the Electric Industry
}

\author{
Chi-Yun Hua ${ }^{1}, \quad$ Min-Li Yao ${ }^{2}$, Wen-Chih Lee ${ }^{3}$, Wei-Ming Chin ${ }^{4}$ \\ ${ }^{1}$ Department of Accounting, Fu-Jen CatholicUniversity \\ ${ }^{2}$ Department of Finance, Ming-Chuan University \\ ${ }^{3}$ Graduate School of Commerce, National Kaohsiung University of Applied Sciences \\ ${ }^{4}$ Deloitte Taiwan
}

\begin{abstract}
The prior studies are focus on the association between merge and acquisition (M\&A) announcement and stockholders' wealth. There are few studies examining the change in the level of information asymmetry at M\&A announcement. Our study, therefore, goes to fill out the aspect. This paper empirically investigates the change in asymmetric information at M\&A announcement with a model proposed by Hasbrouck (1991b) and Brooks (1996). The model uses stock price, bid-ask quote, and trading volume via VAR model to derive a new proxy $\left(\mathrm{R}_{\mathrm{w}}{ }^{2}\right)$ of price variance for the level of asymmetric information among investor. The sample includes 30 firms with the M\&A events in the electronic industry as listed in the Taiwan primary market. The findings indicate that M\&A announcements, based on this study, has information contents but do not effectively reduce the level of asymmetry.
\end{abstract}

Keywords:Merge \& Acquisition Announcement, Market Microstructure, VAR Model, Bid-Ask Spread, Information Asymmetry

\section{Introduction}

The paper use asymmetric information proxy $\mathrm{R}_{\mathrm{w}}{ }^{2}$ measured by price variance and market microstructures to examine the change in asymmetric information at the corporate announcement of merge and acquisition (M\&A).

Most prior studies of M\&A issues put their concerns about the investors' wealth change of acquirer and target companies. They focus on whether mergers increase the combined values of acquirers and targets, how the stock prices response the M\&A event, and what determinants of M\&A are. Besides, most of them apply the Capital Assets Pricing Model (CAPM) and the event study method to examine the abnormal return to see the association between M\&A announcements and price movements (Lin, 2001; Weng, 2002; Lian, 2002). However, there is little literature discussing the information asymmetry during the M\&A process. We, therefore, particularly consider whether there is information asymmetry in M\&A process and give insiders arbitrage opportunities. Base on the change in asymmetric information measurements, the study try to figure out whether the asymmetry between informed traders and uninformed traders reduces at M\&A announcement.

The paper investigates the change in asymmetric information at M\&A announcement with a model proposed by Hasbrouck (1991b) and Brooks (1996). The model uses stock price, bid-ask quote, and trading volume via VAR model to derive price variance as a new proxy (Rw2 ) for the level of asymmetric information among investors. We find that the information asymmetry measurements do not reduce after M\&A announcements, indicating that the announcement has information contents but do not effectively reduce the level of asymmetry.

\section{Research Design}

We use intraday time-ordered data which include bid, ask prices, trade prices, and trade volumes during the research period. The CD-ROM Database from Taiwan Stock Exchange (TSE) provides us those transaction 
data. Our study period is from year 1992 to 2001 . There are 30 high-tech public listed companies release M\&A announcement during the ten years period.

Our model is based on Hasbrouck (1991b) and Brooks' (1996) Vector Autoregressive Regressions. The models are:

$$
\begin{aligned}
& R_{t}=\alpha_{1} R_{t-1}+\alpha_{2} R_{t-2}+\cdots+\beta_{0} X_{t}^{0}+\beta_{1} X_{t-1}^{0}+\cdots \\
& +\gamma_{0} X_{t}^{1}+\gamma_{1} X_{t-1}^{1}+\cdots+\delta_{0} X_{t}^{2}+\delta_{1} X_{t-1}^{2}+\cdots+v_{1, t} \\
& X_{t}^{i}=\phi_{i, 1} R_{t-1}+\phi_{i, 2} R_{t-2}+\cdots+\eta_{i, 1} X_{t-1}^{0}+\eta_{i, 2} X_{t-2}^{0}+\cdots \\
& +\lambda_{i, 1} X_{t-1}^{i}+\lambda_{i, 2} X_{t-2}^{1}+\cdots+\psi_{i, 1} X_{t-1}^{2}+\psi_{i, 2} X_{t-2}^{2}+\cdots+v_{i t 2, t}
\end{aligned}
$$

Where: $R_{t}$ is Quote revision, measured from midpoint at time $t$ minus the midpoint at time $t-1$. The midpoint at time $t$ is the average price of bid and ask quoted; $\mathrm{i}$ is 0,1 or $2 ; \mathrm{X}_{0 \mathrm{t}}$ is signed trade. When the price is greater than the quote midpoint, we assume that is a buy order. The sign will be $(+1)$; otherwise, the sign will be $(-1)$. If the price equal to the quote midpoint, the sign will be 0 since we are unable to judge the direction. $X_{1 t}$ measures the size of trade. $X_{2 t}$ equals to $X_{0 t}\left(X_{1 t}\right)^{2}$. $V_{t}$ is residual terms.

The economic content of the above model comes from the interpretation of the residuals $\left(\mathrm{V}_{\mathrm{i}, \mathrm{t}}\right)$.The information content of residuals has two parts: nontrade public information enter the model as quote revision innovation $\left(\mathrm{V}_{1, \mathrm{t}}\right)$ and private information enter the model as trade innovation $\left(\mathrm{V}_{\mathrm{i}+2, \mathrm{t}}\right)$. Afterward, we can link the residual, VAR and random-walk together to form Vector Moving Average (VMA). See equations 3 and 4.

$$
\begin{aligned}
R_{t}= & v_{1, t}+\alpha_{1}^{*} v_{1, t-1}+\alpha_{2}^{*} v_{1, t-2}+\cdots+\beta_{0}^{*} v_{2, t}+\beta_{1}^{*} v_{2, t-1}+\cdots \\
& +\gamma_{0}^{*} v_{3, t}+\gamma_{1}^{*} v_{3, t-1}+\cdots+\delta_{0}^{*} v_{4, t}+\delta_{1}^{*} v_{4, t-1}+\cdots
\end{aligned}
$$

$$
\begin{aligned}
X_{t}^{i}= & \phi_{i, 1}^{*} v_{1, t-1}+\phi_{i, 2}^{s} v_{1, t-2}+\cdots+\eta_{i, 1}^{*} v_{2, t-1}+\eta_{i, 2}^{*} v_{2, t-2}+\cdots \\
& +\lambda_{i, 1}^{*} v_{3, t-1}+\lambda_{i, 2}^{*} v_{3, t-2}+\cdots+\psi_{i, 1}^{*} v_{4, t-1}+\psi_{i, 2}^{*} v_{4, t-2}+\cdots
\end{aligned}
$$

The above models rely on the key assumption that the two disturbances $\left(\mathrm{V}_{1, \mathrm{t}}\right.$ and $\mathrm{V}_{\mathrm{i}+2, \mathrm{t}}$ ) are uncorrelated with the contemporary and lagged repressors. If the quote revisions and trade are jointly covariance stationary and VMA is reversible, we can link VAR and VMA together. Besides, according to efficient market hypothesis, the price variance can decompose to three parts; see equations 5, 6, 7 and 8 .

$$
\sigma_{w}^{2}=\sigma_{w, x}^{2}+\sigma_{u}^{2}
$$

Where, $\sigma_{W}^{2}$ is efficient price variance due to random-walk. $\sigma_{w, x}^{2}$ measures efficient price variance attributable to trading. $\sigma_{u}^{2}$ is efficient price variance cannot attributable to trading.

$$
\begin{aligned}
\sigma_{u}^{2}= & \sigma_{1}^{2}\left(\sum_{0}^{\infty} \alpha_{i}^{* *}\right), \\
\sigma_{w, x}^{2}= & \sigma_{2}^{2}\left(\sum_{i=1}^{\infty} \beta_{i}^{*}\right)+\sigma_{3}^{2}\left(\sum_{i=1}^{\infty} \gamma_{i}^{*}\right)+\sigma_{4}^{2}\left(\sum_{i=1}^{\infty} \delta_{i}^{*}\right) \\
& +2 \sigma_{2,3}\left(\sum_{i=1}^{\infty} \beta_{i}^{*} \gamma_{i}^{*}\right)+2 \sigma_{2,4}\left(\sum_{i=1}^{\infty} \beta_{i}^{*} \delta_{i}^{*}\right)+2 \sigma_{3,4}\left(\sum_{i=1}^{\infty} \gamma_{i}^{*} \delta_{i}^{*}\right)
\end{aligned}
$$

Where, $\sigma_{i, j}$ is covariance of residuals $\mathrm{Vi}$ and $\mathrm{Vj}$

According to above models, we are able to get $\mathrm{R}_{\mathrm{w}}{ }^{2}$ which is the efficient price variance attributable to market trading Equation 8 shows how we can calculate $\mathrm{R}_{\mathrm{w}}{ }^{2}$

$$
R_{w}^{2}=\sigma_{w, x}^{2} / \sigma_{w, x}^{2}+\sigma_{u}^{2}
$$

Our study first calculates the price variance of those 30 high-tech companies which conduct M\&A during the event period. Then, we take market microstructure as a contrast model to do the analysis. To test the change of asymmetric information, we calculate average number for $\mathrm{R}_{\mathrm{w}}{ }^{2}$, bid-ask spread and trading volumes for each firms during estimation period and during event period first. In advance, Wilcoxon Sign Rank test is utilized to compare the difference between the event period estimate and nonevent period estimate.

In the study, announcement day is the date that firms announce M\&A named as event day. Event period includes 68 trading days which are 60 days before and 7 days after the event day. Estimation period includes 31 days before the event day till 60 days before the event.

\section{Empirical Analysis and Results}

We find that there are significant differences between the change of $\mathrm{R}_{\mathrm{w}}{ }^{2}$, bid-ask spread, trading volumes during event period and nonevent period. In terms of $\mathrm{R}_{\mathrm{w}}{ }^{2}$, we find the value is relative higher for 20 days prior to the announcement day. After the announcement day, it reverses back to the average level. The pattern of $\mathrm{R}_{\mathrm{w}}{ }^{2}$ is pretty volatile comparing with the other two variables. It implies the inflow of private information have huge impact on the intraday trading. Thus, the information asymmetry exists during the event period. In terms of bid-ask spread, it is very volatile if looks as a whole; in general the spread is smaller during nonevent period. However, the spread gets larger when it gets closer to the announcement day. The speed decreases after the event day. In terms of trading volumes, the 
volumes are quiet high during the 12th to the 27 th days prior to the announcement day. The trading volumes are bigger after the event day than prior the announcement day. This suggests that the announcement of M\&A has certain information content for the market participants. In sum, the trading volumes during the event period are higher than the nonevent period (See fig. 1, 2 and 3).

From table 1, we can see that $\mathrm{R}_{\mathrm{w}}{ }^{2}$ in general is positive during event period. Negative sign appears only at the 27 th day prior to announcement day. This means the level of information asymmetry during event period is higher compare to nonevent period. We find that most Ave. $\%$ are positive. The student's $t$ tests are significant. In average, $80 \%$ firms' $\mathrm{R}_{\mathrm{w}}{ }^{2}$ at an event day is larger than that at a nonevent day. Besides, the price variance attributed to trading is higher at the day before announcement day. In other words, the level of information asymmetry is practically high at the day before the announcement day. Since the M\&A deal is very clear one day prior to the announcement, people holding private information actively participate to get profits from uninformed traders (Hasbrouck, 1991b; Books 1996). After the announcement day, the level of asymmetric information is not diminished. $\mathrm{R}_{\mathrm{w}}{ }^{2}$ is relatively higher compared to nonevent period. In the 7 th day after the announcement, there is no significant difference of price variance between the event day and nonevent day, indicating that the detail information of M\&A is not fully announced at the announcement day and cause information asymmetry exists even after announcement day. From the Market Observation Post System (M.O.P.S.), we found that when a firm announces M\&A, they only mention the M\&A is going to happen. They don't release any information about the method of payment, how the stock will transfer, how the two companies are going to combined and what benefits will produced by the M\&A. This example shows us that at the announcement day, the information announcement is not complete. Only insiders know weather M\&A is a good news or bad news.

About Rel. Spread, its trend is very similar to the value of $\mathrm{R}_{\mathrm{w}}{ }^{2}$. The majority values of Ave. $\%$ are negative but Student's t tests don't show significance. From this we know bid-ask spread reflects less private information. The level of information asymmetric is not critical among traders. We may say that specialists don't expect any inflow of new information or all traders in the market have same expectation of the M\&A activity. Or, it is a bad information for the insiders, so they are neutral in their investment and not doing any participation. The price is not impact by the information.

In terms of trading volumes, the majority of the Ave. is positive and Student's t shows significant, too. In average, 95\% firms' volumes at an event day are larger than that at a nonevent day. The trading volumes are significantly increased at the day and after the announcement, showing that investors actively participate in the market after perceiving the information. The results consists with Lin (2001) study which concludes that trading volumes of the bidding firms increase at the day and after the announcement. Generally, huge trading volumes are accompanies with increased bid-ask spread which has positive relation with the level of information asymmetry. Trading volumes imply the level of private information (Easley and O'Hara, 1992b). Our study shows that even the trading volumes are bigger in the event period compared to nonevent period, the price variance due to the trading is decreased. This means that the announcement of M\&A slowly reduces the difference between informed and uninformed traders (Books, 1996). It provides a level of playing field.
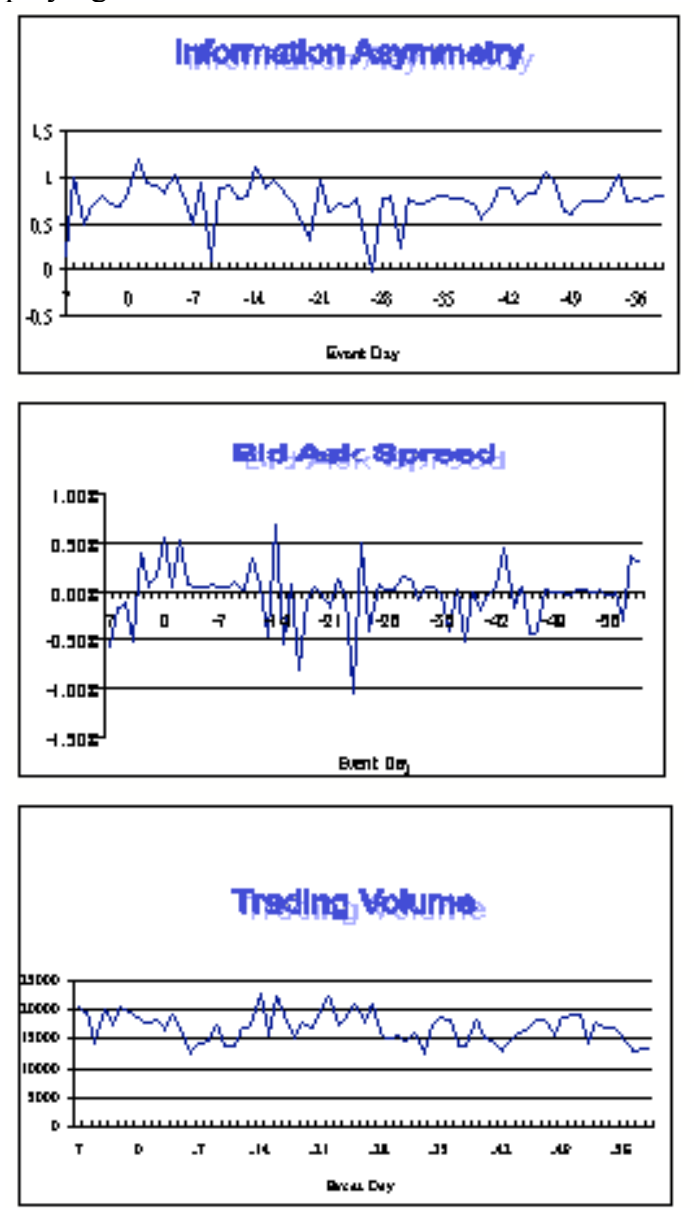

Fig. 1: Trend of Information Asymmetry, Bid-Ask Spread and Trading Volumes 
Notes :Announcement day is Day 0, Negative sign is for the day prior to the announcement, Positive sign is for the day after announcement day.

\section{Conclusions and Suggestions}

The major purpose of our study is to investigate how the level of information asymmetry, bid-ask spread, trading volumes change during event period. We are not trying to exam any hypotheses of information content Our study finds out that $\mathrm{R}_{\mathrm{w}}{ }^{2}$, bid-ask spread and trading volumes are significantly higher during the 68 trading day in event period than nonevent period. It indicates the information asymmetry is critical during event period $\mathrm{R}_{\mathrm{w}}{ }^{2}$ is much higher for 20 days prior to the announcement day which implies that price is impact by the inflow of private information. The result consists with Keown and Pinkerton (1981). Bid-ask spread is not significant during the event period, indicating no significant difference in terms of information asymmetry between event period and nonevent period. This may due to all the traders have same expectation about the information. Or, it is bad information. As a result, they hold their investment and not doing any participation. This result is different from our $\mathrm{R}_{\mathrm{w}}{ }^{2}$ measurements. Thereby, previous studies only take bid-ask spread to measure the level of information asymmetry is not exactly accurate. Although we find the trading volumes continuously increase, big trading volume doesn't necessary mean the enlarge of information asymmetry (the 7 th day after announcement day as an example), we also need to consider the change of bid-ask spread and $\mathrm{R}_{\mathrm{w}}{ }^{2}$ to get better understanding weather the level of information asymmetry is getting severe or not. According to our findings, the level of information asymmetry is not reduced after the announcement, although the difference of mean is lightly decreasing. Therefore, private information holders are still having advantage compare to uninformed traders.

\section{References}

[1] Brooks, R. M., "Changes in Asymmetric Information at Earnings and Dividend Announcements," Journal of Business Finance \& Accounting, 23, 3, pp. 359-378, 1996.

[2] Easley, D., \& O`Hara, M., "Adverse Selection and Large Trade Volume," Journal of Financial and Quantitative Analysis, 27, 2, pp. 185-208, 1992a.

[3] Easley, D., \& O'Hara, M., "Time and the Process of Security Price Adjustment," The Journal of Finance, 47, 2, pp. 577-605, $1992 b$.

[4] Hasbrouck, J., "Measuring the Information Content of Stock Trades," The Journal of Finance, 46, 1, pp. 179-207, 1991a.

[5] Keown, Arthur J. \& Pinkerton, John M., "Merger Announcement and Inside Trading Activity: an Empirical Investigation," The Journal of Finance, 36, pp. 855-869, 1981.

[6] Lian, Y. D., "The Impact of Payment Methods on Stock Price Performance," Unpublished Master Thesis form Department of Business Administration, National Chung Cheng University, 2002.

[7] Lin, X. C., "The Effect of M\&A Announcement on Stock Price: Evidence form IT Industry," Unpublished Master Thesis from Department of Business Administration, National Chengchi University, 2001.

[8] Weng, Y. J., "The Impact of M\&A Announcement on Competitors' Stock Price - Evidence from TSE Listed Firms," Unpublished Master Thesis form Executive Master of Business Administration, National Cheng Kung University, 2002.

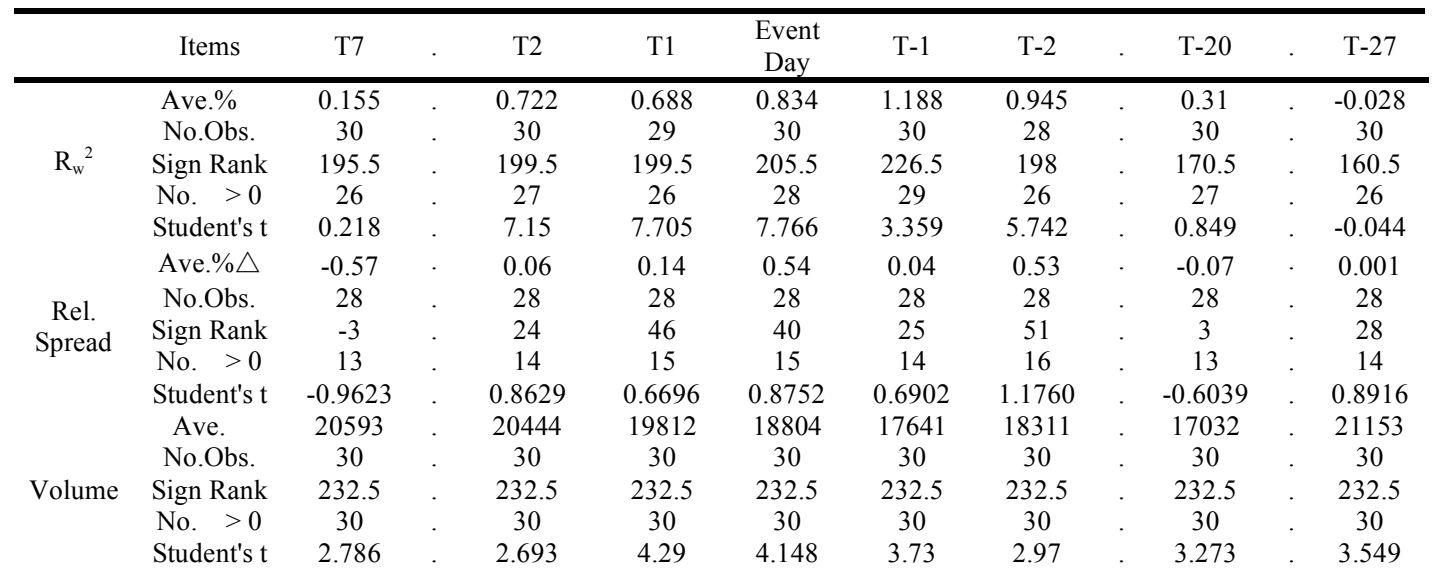




\section{Table 1: Wilcoxon Sign Rank Test of $R_{W}^{2}$, Relative Spread, Trading Volumes}

Notes: $\mathrm{R}_{\mathrm{w}}{ }^{2}$ is the price variance attributed to trades. Rel. Spread is the lowest standing ask minus the highest standing bid all divided by the last transaction price. Volume is the number of round lots traded The Ave. \% is average percentage change across the sample and is the daily estimate of each firm for the event day minus the nonevent period average for that individual firm. The change in volume (Ave. ) is the average change in volume for the sample and is computed using each individual firm's daily volume minus the firm's nonevent period average. The number of observation (No. Obs.) is the number of M\&A announcements during 1992 to 2001 and without any major contaminating events. This sign rank statistic is computed from the Wilcoxon sign rank test. No. $>0$ is the number of observations with increases in the measure for that event day. Student's $t$ is the significance of the statistic. Our event period includes 68 trading days. However, Table 1 only reports the variance on the days is more significant than that on others. 